\title{
Effects of patient education on compliance with basic treatment regimens and health in recent onset active rheumatoid arthritis
}

\author{
Herman L M Brus, Martin A F J van de Laar, Erik Taal, Johannes J Rasker,
} Oene Wiegman

\begin{abstract}
Objectives-To determine the effects of patient education on compliance and on health in patients with active, recent onset rheumatoid arthritis (RA).

Methods-A randomised, controlled, assessor blinded, one year trial. The experimental group followed an education programme. All patients started on sulphasalazine therapy. Compliance with sulphasalazine was measured by pill counting. Compliance rates with regimens of physical exercise, endurance activities, and energy conservation were measured by questionnaires. Compliance with prescriptions of joint protection was scored using a test for joint protection performance. Health was measured by a Disease Activity Score (function of erythrocyte sedimentation rate, Ritchie score, and number of swollen joints), $C$ reactive protein, Dutch-AIMS scores, and M-HAQ scores, range of motion of shoulder, elbow, and knee joints. Parameters were scored at baseline and after three, six, and 12 months.
\end{abstract}

Results-Sixty of 65 patients gave informed consent, five of them withdrew from follow up. Compliance with sulphasalazine exceeded $80 \%$ with no differences between groups. Compliance with physical exercise (at three months), energy conservation (at three and at 12 months), and joint protection (at three months) improved significantly more in the experimental group. The improvements of health were not different in the groups.

Conclusion-Compliance with sulphasalazine among patients with active, recent onset $R A$ is high, whether formal patient education is followed or not. Compliance with physical exercise, energy conservation, and joint protection was increased by patient education. Formal patient education did not improve health status.

(Ann Rheum Dis 1998;57:146-151)

The treatment of rheumatoid arthritis (RA) is a multidisciplinary effort. ${ }^{1}$ For recently developed RA medication, exercise, and ergonomic measures are generally used..$^{1-5}$ In this study we refer to this combination of regimens as basic treatment. The success of any treatment depends upon the compliance of the patient as well as upon the efficacy of the treatment itself. Compliance or adherence, has been defined as "the extent to which a persons behaviour coincides with the medical or health advice".

The few studies that dealt with compliance with regimens of basic treatment among RA patients suggested that it is low. ${ }^{7-17}$ Estimates of compliance with non-steroidal antiinflammatory drug (NSAID) therapy range from $58 \%$ to $73 \%$ (prescribed medication taken) or from $63 \%$ to $78 \%$ (patients considered compliant).$^{7-9}$ Deyo et al found a compliance with disease modifying anti-rheumatic drug (DMARD) therapy (d-penicillamine) of $84 \%$ (pills prescribed that were actually dispensed) during a six month study of only nine RA patients. ${ }^{9}$ Pullar et al used a pharmacological indicator in a study on compliance among RA patients and found $58 \%$ of them to be compliant. ${ }^{10}$ Doyle et al used a urinary assay for d-penicillamine metabolites for the compliance of RA patients who used d-penicillamine. They found that $39 \%$ of patients were poorly compliant. ${ }^{11}$ Compliance with regimens of physical exercise was found to vary between $43 \%$ and $65 \% .^{8}{ }^{12-14}$ Studies of compliance with prescriptions for ergonomic measures in clinical practice dealt only with the use of wrist splints during periods that patients are physically active. These yielded a compliance of $47 \%$ to $52 \%$. $^{15} 16$

Until now no studies have been performed that consider systematically the effects of patient education on compliance and related effects on health status. Lorig et al, Lindroth et al, and Taal et al achieved improvements of health behaviour by patient education. Adherence to prescription of physical exercise was considered in these studies. ${ }^{18-21}$ Only Lindroth et al found effects on compliance with ergonomic measures. ${ }^{21}$ These studies did not take medication into account. The improvements in health status found regarded pain and physical function in patients suffering from RA, osteoarthritis, and other arthritides. Besides enhancement of compliance with basic treatment the programmes had other goals: relaxation, coping with depression and with communication problems. The absence of a systematic measurement of compliance with basic treatment makes it difficult to analyse the relation between compliance and health in these studies.

Lorig et al, Taal et al applied patient education programmes based on Bandura's social learning theory. This theory contends that 
human functioning involves a continuous interaction between behaviour, personal factors, and environment. ${ }^{22}{ }^{23}$ The personal factor self efficacy expectation (briefly: self efficacy) was postulated as an important determinant of behaviour. It refers to one's belief that one can perform a specific behaviour in the future. An enhancement of self efficacy expectation is strived for to achieve a change in behaviour.

Self efficacy expectations can be enhanced by performance accomplishments, vicarious experience, persuasive communication, and the correction of false interpretations of physiological state. As a consequence the goals set in patient education programmes must be attainable. Moreover, patients must have the necessary skills before a related treatment advice can be adequately followed. Vicarious experience is often used in group education, where other patients can act as models; seeing people similar to oneself succeed raises one's beliefs about one's own capabilities. Prudence is called for in the use of persuasion, as unrealistically high self efficacy expectations can cause failure..$^{22-24}$

Until now, the effect of patient education on compliance with DMARD therapy has not been investigated. Based on the social learning theory, an educational programme, was developed aiming to improve compliance with basic treatment. In this study we firstly consider the effects of this programme on compliance with sulphasalazine therapy, physical exercises and endurance exercises, prescriptions for ergonomic measures. Secondly, the effects on health are studied.

\section{Methods}

PATIENTS

Consecutive patients, being treated in our outpatient clinics or referred to us by their family doctors, suffering from RA (ACR criteria ${ }^{25}$ ) for less than three years were recruited by six rheumatologists. Active disease was defined by an erythrocyte sedimentation rate (ESR) greater than $28 \mathrm{~mm} \mathrm{1st}$ hour, the presence of six or more painful joints, and the presence of three or more swollen joints. DMARD therapy with sulphasalazine had to be indicated by the attending rheumatologist and agreed for by the patients. Patients who had used any DMARD other than hydroxychloroquine were excluded.

\section{STUDY DESIGN}

The study was designed as a randomised, controlled, assessor blinded, clinical trial. It was intended to follow up all patients for one year. Patients were allocated at random to the experimental or control group. The randomisation was carried out blockwise per rheumatologist. Thereafter the patients were asked to give informed consent for the group to which they were assigned. ${ }^{26}{ }^{27}$ The experimental group attended six patient education meetings. The control group received a brochure on RA, as provided by the Dutch League against Rheumatism. This brochure gives comprehensive information on medication, physical and occupational therapy. Sulphasalazine in the form of $500 \mathrm{mg}$ enteric coated tablets was prescribed to all patients. The daily dose was increased in four weeks by steps of one tablet, until a daily dose of four tablets was reached. In individual cases, this could be increased to six tablets a day, reduced as deemed necessary, or stopped in case of inefficacy or toxicity, at the discretion of the attending rheumatologist. All patients obtained the sulphasalazine tablets from the pharmacists according to the local Health Care System.

\section{EDUCATION PROGRAMME*}

Our education programme focused on compliance with sulphasalazine therapy, physical exercises, endurance activities (walking, swimming, bicycling), advice on energy conservation, and joint protection. Four (two hour) meetings were offered during the first month. Reinforcement meetings were given after four and eight months. The programme was implemented in groups and partners were invited to attend the meetings. One instructor (HB) provided information on RA, attendant problems, and basic treatment. The related beliefs of the patients were discussed and, when necessary, corrected. If patients anticipated problems with the application of any of the treatments, these were discussed, including possible solutions. A training was given in proper execution of physical exercises. Patients were encouraged to plan their treatment regimens. Their intentions were discussed and help was given in recasting unrealistic ones. Patients made contracts with themselves regarding their intentions. Feedback on the eventual implementation of therapeutic advice was included in each meeting.

\section{MEASUREMENTS}

Evaluations were made by the same assessor, a measurement technician. He was blinded for the allocation. Age, sex, the number of criteria for the ACR classification, ESR, number of swollen joints and of painful joints were established at the beginning of the study.

Compliance with sulphasalazine therapy was evaluated at three, six, and 12 months. Medical records and pharmacy records were the source of data on the number of tablets prescribed and the number of tablets obtained. At each evaluation, the remaining tablets were counted. Compliance was defined as the number of tablets that had been taken during the preceding period divided by the number of tablets prescribed. If sulphasalazine had been prescribed during only a part of the preceding period, compliance was computed for that part only. At each evaluation, we recorded the number of patients taking sulphasalazine and when applicable the reasons for stopping. We also registered use of other DMARDs or corticosteroids.

The following assessments of compliance were done at baseline and three, six, and 12 months. Compliance rates with prescriptions for physical exercise and with endurance activity regimens (walking, swimming, bicycling) were measured by questionnaire; patients were asked how many times a week and how many

* Additional information on the education programme will be provided by the authors on request. 
Table 1 Sex, age, and disease activity at baseline in the experimental and control group (mean (SD))

\begin{tabular}{lcc}
\hline & $\begin{array}{l}\text { Experimental } \\
(n=25)\end{array}$ & Control $(n=30)$ \\
\hline Women & $23(92 \%)$ & $21(70 \%)$ \\
Age $(y)$ & $59.7(15.0)$ & $58.7(9.2)$ \\
No of ARA criteria & $4.6(.6)$ & $4.8(.8)$ \\
ESR (mm 1st h) & $57.4(36.1)$ & $53.3(24.2)$ \\
No of swollen joints & $2.3(2.5)$ & $2.7(2.4)$ \\
No of painful joints & $14.8(9.2)$ & $13.1(8.5)$ \\
\hline Comparison between groups ${ }^{\star}{ }^{*}<0.05$ &
\end{tabular}

Comparison between groups: ${ }^{\star} \mathrm{p}<0.05$.

minutes average each time they performed these activities. Time spent on endurance activities were added.

Compliance with prescriptions for energy conservation was measured by questioning whether patients spread their activities over the day to prevent fatigue. The question could be answered on a five point scale ranging from 0 (poor performance) to 4 (good performance). A test for joint protection performance was used as an indication of the level of compliance with the prescription of joint protection. Patients were requested to perform actions, representing relevant ergonomic principles. The test score ranges from 0 to 10 , where 0 represents a poor performance and a 10 good performance. ${ }^{28}$

Disease activity was measured by the disease activity score (DAS) ${ }^{29}$ This is a function of ESR (0-140 $\mathrm{mm}$ 1st hour), Ritchie score $(0-78),{ }^{30}$ and number of swollen joints $(0-52)$. The DAS ranges from 0 to 10 , where 0 represents the lowest level of disease activity possible, and 10 the highest. $C$ reactive protein (CRP) was measured nephelometrically (mg/ 1). Physical function was measured by a Dutch version of the M-HAQ. ${ }^{31}$ This short questionnaire yields a score, which ranges from 1 to 4 , where 1 represents good function and 4 poor function. The Dutch-AIMS questionnaire was used to assess physical function, psychological function, pain, and social activities. ${ }^{32}$ The four dimensions deal with mobility, physical activities, dexterity, household activities, social activities, and activities of daily living. The psychological series concern anxiety and depression. The scores of each series range from 0 to 10 , where 0 represents good health and 10 poor health. Range of motion was assessed, by means of a goniometer in degrees, as exorotation of the shoulders, extension and flexion of the elbows, and extension and flexion of knees.

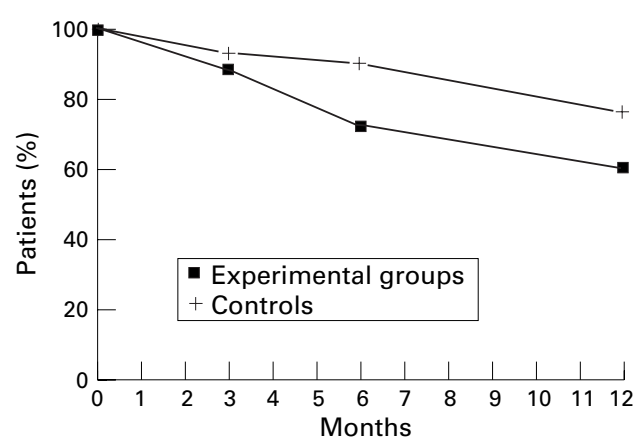

Figure 1 Patients receiving sulphasalazine treatment in experimental and control group in percentages.
STATISTICAL ANALYSIS

The sex distributions and numbers of patients using sulphasalazine in the experimental and control groups were compared with the $\chi^{2}$ test. The Wilcoxon two sample test was used to test the significance of differences in all compliance and health variables between the groups.

ETHICS

The protocol was approved by the ethical committees of the hospitals where the study was performed.

\section{Results}

Sixty five patients were selected. Thirty two were randomised to the experimental condition. Three patients in the experimental group and two in the control group refused informed consent. Sixty patients entered the study: 29 in the experimental condition and 31 in the control. Ten groups of patients received the education programme. Eleven partners attended the meetings. From each group one patient refused the evaluation at six months. Another three patients refused the final evaluation. The results presented here concern the available data on the remaining 25 experimental and 30 control subjects.

The groups were comparable regarding age, number of ACR criteria, ESR, number of swollen joints, and number of painful joints. However, the control group contained more men $(p<0.05)$ (table 1).

In the first quarter compliance with sulphasalazine in the educated patients was 91 (12)\% (mean (SD)). In the controls compliance was $87(22) \%$. In the second quarter compliance was $82(22) \%$ and $82(28) \%$ respectively. During the third and fourth quarter compliance rates were $89(16) \%$ and 84 (21)\% respectively. There were no statistically significant differences between the groups in any of these periods. After one year, $60 \%$ $(n=15)$ of the patients in the experimental group and $76 \%(n=23)$ in the control group were still using sulphasalazine. The difference is not statistically significant (fig 1). Three patients in the experimental group stopped using sulphasalazine because of inefficacy; seven for adverse reactions. Three patients of these 10 received another DMARD together with a low dose prednisone, four another DMARD alone, and three used neither of these. Seven patients from the control group stopped sulphasalazine (inefficacy: one; toxicity: six). One of these seven patients was using another DMARD in combination with a low dose prednisone, one was using only prednisone, and five were using neither of these.

Time spent on physical exercises and on endurance activities as well as scores regarding energy conservation and scores on the test for joint protection performance were comparable at baseline (table 2). Only at three months the increment of time spent on physical exercises was significantly greater in the experimental group $(\mathrm{p}<0.05)$ (table 2$)$. During the observational period the time spent on endurance exercise did not differ significantly between groups (table 2). The increase that was 
Table 2 Comparison of compliance with regimens of physical exercises, endurance activities, energy conservation, and joint protection between educated group $(n=25)$ and control group $(n=30)$ at baseline and changes between baseline and $3,6,12$ months. Data shown as mean (standard deviation)

\begin{tabular}{|c|c|c|c|c|}
\hline & Baseline & $\begin{array}{l}\text { Change between } \\
O \text { and } 3 \text { months }\end{array}$ & $\begin{array}{l}\text { Change between } \\
0 \text { and } 6 \text { months }\end{array}$ & $\begin{array}{l}\text { Change between } \\
0 \text { and } 12 \text { months }\end{array}$ \\
\hline \multicolumn{5}{|c|}{ Physical exercise (min/week) } \\
\hline education & $49(49)$ & $30(42)^{\star}$ & $27(81)$ & $20(79)$ \\
\hline control & $39(34)$ & $4(56)^{\star}$ & $32(119) \mathrm{m} 2$ & $-7(33) \mathrm{m} 1$ \\
\hline \multicolumn{5}{|c|}{ Endurance activities (min/week) } \\
\hline education & $184(167)$ & $28(241)$ & $25(157)$ & $12(180)$ \\
\hline control & $161(157)$ & $-14(111)$ & $10(169)$ & $-34(157) \mathrm{m} 2$ \\
\hline \multicolumn{5}{|c|}{ Energy conservation (scale $0-4$ ) } \\
\hline education & $2.6(1.2)$ & $0.7(1.2)^{\star \star} \mathrm{m} 1$ & $0.2(1.6) \mathrm{m} 1$ & $0.4(1.1)^{\star}$ \\
\hline control & $2.5(1.3) \mathrm{m} 2$ & $-0.1(1.3)^{\star \star} \mathrm{m} 2$ & $-0.2(1.6) \mathrm{m} 3$ & $-0.2(1.3)^{\star} \mathrm{m} 3$ \\
\hline \multicolumn{5}{|c|}{ Joint protection (scale $0-10$ ) } \\
\hline education & $2.2(1.9)$ & $0.9(2.4)^{\star \star}$ & $0.8(2.4)$ & $0.8(2.0) \mathrm{m} 2$ \\
\hline control & $1.5(1.4)$ & $-0.2(1.2)^{\star \star}$ & $-0.2(1.3)$ & $-0.1(1.4) \mathrm{m} 1$ \\
\hline
\end{tabular}

$\mathrm{m}=$ Number missing values. Comparison between groups: ${ }^{\star} \mathrm{p}<0.05,{ }^{\star \star} \mathrm{p}<0.01$.

observed in application of energy conservation was greater in the experimental group and statistically significantly different from the control group at three months $(\mathrm{p}<0.01)$ and at 12 months $(p<0.05)$ (table 2). The change from baseline in the scores on the test for joint protection performance in the experimental group was significantly different from that in the control group at three months $(\mathrm{p}<0.01)$ (table 2$)$.

At baseline the two groups were comparable with respect to DAS, CRP, and M-HAQ. The experimental group scored significantly higher on the mobility scale of the Dutch AIMS at study entry. However, the scores on the other scales of the Dutch AIMS were comparable at that time. The changes from baseline in the DAS, CRP, M-HAQ, and AIMS scales after three, six, and 12 months did not differ significantly between the groups (data not shown). The ranges of motion measured at study entry were within normal limits for both groups. Also, throughout the study no relevant differences occurred (data not shown).

Analysis of the patients that were available at three months (one withdrawal), of those available at six months (three withdrawals) and of the female patients yield results comparable to those presented in this report (data not shown). These analysis suggest that withdrawals and sex distribution did not influence the results.

\section{Discussion}

Patient education comprises "all planned educational activities aimed at assisting patients in achieving voluntary health behaviour changes". ${ }^{33}$ Therefore compliance with treatment regimens is the primary outcome to be measured in this study. Health status variables are the secondary outcome measures.

To avoid confounding all patients were treated with the same DMARD (sulphasalazine). To avoid patient bias, informed consent had to be differentiated according to experimental condition. Patients were randomised after selection by their rheumatogists but before asking informed consent. This procedure has been described by Zelen. ${ }^{26}{ }^{27}$ However, in contrast with Zelen, patients who refused to join the experimental group were not invited to join the control group. The numbers of patients refusing to give informed consent, three for the experimental and two for the con- trol condition, in our opinion were acceptably low. In the control group more men were included. Therefore questioning the presence of selection is applicable. However, the results of a separate analysis of female patients did show comparable results. According to the described randomisation procedure the attending rheumatologists selected the patients. Therefore, at inclusion, the data on disease activity as scored by the independent measurement technician, did not always fulfil the selection criteria, but according to the protocol patients were included because they were selected previously. Five patients from the experimental and two from the control group refused follow up evaluations. It is unlikely that the withdrawal of these five patients has an impact on our findings: the results of separate analyses at three months and at six months were similar to those represented in this paper. Selection bias was avoided by blockwise randomisation per rheumatologist. Therefore we did not evaluate the instructions given by individual rheumatologist. To ensure that the control patients were instructed sufficiently they received a brochure about RA and its treatment that included information regarding physical therapy and occupational therapy.

Pill counting procedures seem to be more accurate for evaluating compliance than interviews with patients or their clinicians, but less accurate than the use of pharmacological indicators. ${ }^{10}{ }^{17}$ Recently electronic measurement systems have also received attention. ${ }^{34}$ Electronic systems, however, may influence compliance by confronting patients daily with the fact of their being monitored.

Although the literature generally indicates low rates of compliance with basic treatment regimens, our results suggest that in our clinics high levels of compliance with DMARD therapy are obtained in patients with active, recent onset RA. This is in concurrence with Owen et al who found that patients with high disease activity tend to be more compliant with treatment advice than those with a low disease activity. ${ }^{35}$ It may be argued that patients are compliant because they are cooperating in a clinical trial. In our study the patients in the control group who were not aware of an intervention were also compliant. Moreover, low compliance rates with medications have been reported in clinical trials as well. ${ }^{17} 3637$ 
Questionnaires are commonly used to evaluate compliance with exercise therapies. Questionnaires on exercises do not provide qualitative information and are sensitive for patient bias. In accordance with most other studies, our data suggest that education increases compliance with regimens of physical exercise. ${ }^{19-21} 38-40$

There are no standard measures or methods for the assessment of compliance with prescriptions for ergonomic measures. In some studies the use of devices is assessed, ${ }^{41}$ in others self report by patients of ergonomic performance is used, which is subject to recall and accuracy problems. ${ }^{42}{ }^{42}$ Gerber et al used diaries. However, patients' behaviour might be influenced by the fact that they keep a diary. ${ }^{434}$ Hammond developed a test for joint protection performance that is quite elaborate. ${ }^{45}$ For this study we developed a practicable clinic based measure of observable joint protection behaviour that has been proved to be reliable for RA patients. ${ }^{28}$ It could be argued that we measured the ability to perform joint protection rather than compliance with the prescription of joint protection advice. Our data show an improvement in compliance in energy conservation and joint protection after patient education (table 2). It remains possible that the methods we used for measuring compliance with prescription of ergonomic measures do not reflect the daily practice of the patients. Our results are in concordance with other studies that indicate that patient education might improve ergonomic performance. ${ }^{17-47}$

Surprisingly, the data show that patients were compliant with DMARD therapy, whether they followed the education programme or not. As a consequence the improvement of health status observed is comparable with the effect found in other studies with sulphasalzine in RA. ${ }^{48}$ Moreover, an additional effect of patient education on health could not be found. Data are lacking on the relation of physical exercise and ergonomic measures on the one hand and health status in RA on the other. Although we did not find an influence on range of motion, it is possible that patients with more severely impaired function might benefit from the observed enhanced compliance with physical exercise and ergonomic measures. Moreover, it is probable that the power of this study is insufficient to show a relation between increased compliance with regimens of physical and occupational therapy and health. Although other studies contained larger number of patients, these studies suffer from possible confounding by medication. ${ }^{21-24}$

In our study we applied reinforcement meetings at four months and at eight months. Compliance rates with prescribed therapies was measured at six months and at 12 months. At 12 months positive effects of education were still found on compliance with energy conservation. Whether the reinforcement meetings have helped to maintain effects of patient education remains to be proved.

The results of the study suggest that the compliance of patients with active, recently developed RA with sulphasalazine therapy is high whether they have been exposed to formal patient education or not. Education did have positive effects on compliance with regimens of physical exercise and prescriptions for ergonomic measures. The study suggests that the applied patient education programme has no effect on the health status of patients suffering from active, recent onset RA.

The study was supported by a grant from the National Commissie Chronisch Zieken (National Committee for the Chronically Ill)

The authors wish to thank the pharmacists who cooperated with our study, and Huub Overmars who performed the measurements.

1 American College of Rheumatology Ad Hoc Committee on Critical Guidelines. Guidelines for the management of rheumatoid arthritis. Arthritis Rheum 1996;39:713-22.

2 Brooks PM, Day RO. Nonsteroidal antiinflammatory drugs: differences and similarities. N Engl J Med 1991;324:171625 .

3 Cash JM, Klippel JH. Second-line drug therapy for rheumatoid arthritis. N Engl J Med 1994;330:1368-75.

4 Ytterberg SR, Mahowald ML, Krug HE. Exercise for arthritis. Baillieres Clin Rheumatol 1994;8:161-89.

5 Helewa A, Goldsmith CH, Lee P, Bombardier C, Hanes B, Smythe HA, et al. Effects of occupational therapy home service on patients with rheumatoid arthritis. Lancet 1991; 337:1453-6

6 Haynes RA, Taylor RB, Snow JC, Sackett DL. Annotated and indexed bibliography on compliance with therapeutic and preventive regimens. In: Haynes RB, Taylor DW, Sacket PL, eds. Compliance in health care. Baltimore: John Hopkins University Press, 1997.

7 Lee P, Tan WP. Drug compliance in outpatients with rheumatoid arthritis. Aust NZ J Med 1979;9:274-7.

8 Ferguson K, Bole GG. Family support, health beliefs, and therapeutic compliance in patients with rheumatoid arthritis. Patient Counselling and Health Education 1997;1: $101-5$.

9 Deyo RA, Inui TS, Sullivan B. Noncompliance with arthritis drugs: magnitude, correlates, and clinical implications. J Rheumatol 1981;8:931-6.

10 Pullar T, Peaker S, Martin M,Bird H,Feely M. The use of a pharmacological indicator to investigate compliance in patients with a poor response to antirheumatic therapy. $\mathrm{Br}$ J Rheumatol 1988;27:381-4.

1 Doyle DV, Perrett D, Foster OJF, Ensor M, Scott DL. The long-term use of d-penicillamine for treating rheumatoid arthritis: Is continuous therapy necessary ? Br J Rheumatol 1993;32:614-17.

12 Treusch JV, Krusen FH. Physical therapy applied at home for arthritis. Arch Intern Med 1943;72:231-8.

13 Parker LB, Bender LF. Problem of home treatment in arthritis. Arch Phys Med Rehabil 1957;38:392-4.

14 Carpenter JO, Davis LJ. Medical recommendations followed or ignored? Factors influencing compliance in arthritis. Arch Phys Med Rehabil 1976;57:241-6.

15 Nicholas JJ, Gruen H, Weiner G, Crawshaw C, Taylor F. Splinting in rheumatoid arthritis: 1. Factors affecting Splinting in rheumatoid arthritis: 1. Factors affecting p2-4.

16 Spoorenberg A, Boers M, van der Linden S. Wrist splints in heumatoid arthritis: A question of belief? Clin Rheumatol 1994;13:559-63.

17 Brus HLM, van de Laar MAFH, Taal E, Rasker JJ, Wiegman O. Compliance in rheumatoid arthritis and the role of formal patient education. Semin Arthritis Rheum 1997;26:702-10.

18 Lorig K, Lubeck D, Kraines RG, Seleznick M, Holman HR. Outcomes of self-help education for patients with arthritis. Arthritis Rheum 1985;28:680-5.

19 Taal MA, Riemsma RP, Brus HLM, Seydel ER, Rasker JJ, Wiegman O. Group education for patients with rheumatoid arthritis. Patient Education and Counselling 1993;20:17787.

20 Lindroth Y, Bauman A, Barnes C, McCredie M, Brooks PM. A controlled evaluation of arthritis education. Br J PM. A controlled evaluation

21 Lindroth Y, Bauman A, Brooks PM, Priestley. A 5-year follow-up of an arthritis education programme. Br J Rheumatol 1995;34:647-52.

22 Taal E, Rasker JJ, Wiegman O. Patient education and self-management in the rheumatic diseases: A self-efficacy approach. Arthritis Care Res 1996;9:229-38.

23 Bandura A. Social foundations of thought and action: $A$ social cognitive theory. Englewood,NJ: Prentice-Hall, 1986.

24 Lorig K, Gonzalez V. The integration of theory with practice: A 12-year case study. Health Educ Q 1992;19: 355-68.

25 Arnett FC, Edworthy SM, Bloch DA, McShane DJ, Fries JF, Cooper NS, et al. The American Rheumatism Association 1987 revised criteria for the classification of rheumatoid arthritis. Arthritis Rheum 1988;31:315-24.

26 Zelen M. A new design for randomized clinical trials. N Engl J Med 1979;300:1242-5.

27 Pocock SJ. Clinical trials: 108-109. Avon: The Bath Press, 1988. 
28 Brus H, van de Laar M, Oosterveld F, van Bussel A, Rasker JJ. Betrouwbaarheid van een test voor ergonomie: faarboek Ne-6827-071-0.

29 van der Heijde DMFM, van't Hof MA, van Riel PLCM Theunisse LM, Lubberts EW, van Leeuwen MA, et al Judging disease activity in clinical practice in rheumatoid arthritis: First step in the development of a disease activity score. Ann Rheum Dis 1990;49:916-20.

30 Ritchie DM, Boyle JA, McInnes JM, Jasani MK, Dalakos TG, Grieveson P, et al. Clinical studies with an articular index for the assessment of joint tenderness in patients with rheumatoid arthritis. Q J Med 1968;37:393-406.

31 Pincus T, Calahan LF, Brooks RH, Fuchs HA, Olsen NJ, Kaye JJ. Self-report questionnaire scores in rheumatoid arthritis compared with traditional physical, radiographic and laboratory measures. Ann Intern Med 1989;110:259and 66 .

32 Taal E, Jacobs JW, Seydel ER Wiegman O, Rasker JJ. Evaluation of the dutch arthritis impact measurement scales ation of the dutch arthritis impact measurement scales
(Dutch-AIMS) in patients with rheumatoid arthritis. Br J (Dutch-AIMS) in patients with

33 Green LW, Krueler M, Patridge KB, et al. Health education planning: A diagnostic approach . Mayfield, CA: Palo, 1979.

34 Cramer JA, Mattson RH, Pervey ML, Schreyer RD Ouellette VL. How often is medication taken as prescribed ?: A novel assessment technique. JAMA 1989;261:3273-7.

35 Owen SG, Friesen WT, Roberts MS, Flux W. Determinant of compliance in rheumatoid arthritic patients assessed in their home environment. Br J Rheumatol 1985;24:313-20.

36 Belcon MC, Haynes RB, Tugwell P. A critical review of compliance studies in rheumatoid arthritis. Arthritis Rheum 1984;27:1227-33.

37 Feinberg J. The effect of patient-practitioner interaction on compliance: A review of the literature and application in rheumatoid arthritis. Patient Education and Counselling 1988;11:171-87.
38 Carpenter JO, Davis LJ. Medical recommendations -followed or ignored ? Factors influencing compliance in ; 6 ;57:241-6

39 Potts MSW, Brandt KD. Analysis of education-support groups for patients with rheumatoid arthritis. Patient Counselling and Health Education 1983;4:161-6.

40 Budesheim Neuberger G, Vogel Smith K, Oetker Black S, Hassanein R. Promoting self-care in clients with arthritis. Arthritis Care Res 1993;6:141-8.

41 Nordenskold U: Evaluation of assistive devices after a course in joint protection. Int J Technol Assess Health Care 1994;10:293-304.

42 Kaye RL, Hammond AH. Understanding rheumatoid arthritis: evaluation of a patient education program. JAMA 1978;239:2466-7.

43 Gerber L, Furst G, Shulman B, Smyth C, Thornton B. Patient education program to teach energy conservation behaviors to patients with rheumatoid arthritis: A pilot study. Arch Phys Med Rehabil 1987;68:442-5.

44 Furst GP, Gerber LH, Smith CC, Fisher S, Shulman B. A program for improving energy conservation behaviors in adults with rheumatoid arthritis. Am J Occup Ther adults with rheum

45 Hammond A. Joint protection behaviour in patients with rheumatoid arthritis following an education program. Arthritis Care Res 1994;7:5-9.

46 Hammond A. Helping arthritis patients adopt hand joint protection behaviours. Arthritis Rheum 1994;37(suppl): 290.

47 Barry MA, Pursor J, Hazleman R, McLean A, Hazleman BL. Effect of energy conservation and joint protection education in rheumatoid arthritis. Br J Rheumatol 1994;33: 1171-4.

48 Van de Heyde DM, van Riel PL, Nuver-Zwart HH, Gribnau FW, van de Putte LB. Effects of hydroxychloroquine and sulphasalazine on the progression of joint damage in rheumatoid arthritis. Lancet 1989;i:1036-8. 